\title{
Traffic Attractors and Congestion in the Urban Context, the Case of the City of Rome
}

\author{
Gaia Gullotta1 ${ }^{1}$, Emanuele Loret ${ }^{1}$, Chris Stewart ${ }^{2}$, Francesco Sarti ${ }^{3}$ \\ ${ }^{1}$ European Space Agency (ESA), Frascati, Italy \\ ${ }^{2}$ Future Systems Department, Earth Observation Programmes Directorate, European Space Agency (ESA), Frascati, Italy \\ ${ }^{3}$ Earth Observation Science Strategy, Coordination and Planning Office, Directorate of Earth Observation, European Space \\ Agency (ESA), Frascati, Italy \\ Email: gaiagullotta@gmail.com, loret@disp.uniroma2.it,chris.stewart@esa.int, francesco.sarti@esa.int
}

How to cite this paper: Gullotta, G., Loret, E., Stewart, C. and Sarti, F. (2020) Traffic Attractors and Congestion in the Urban Context, the Case of the City of Rome. Journal of Geographic Information System, 12, 545-559.

https://doi.org/10.4236/jgis.2020.126032

Received: March 19, 2020

Accepted: November 16, 2020

Published: November 19, 2020

Copyright (c) 2020 by author(s) and Scientific Research Publishing Inc. This work is licensed under the Creative Commons Attribution International License (CC BY 4.0).

http://creativecommons.org/licenses/by/4.0/

\begin{abstract}
Traffic flows form a complex system, especially in the context of urban sprawl. Direct estimation of traffic flows requires significant efforts and knowing in advance where to focus the study and where to place tools to directly measure traffic flows, and consequently traffic congestion could lead to significant savings in time and money. In the case of Rome municipality, we have monitored a situation in which a very high rate of urban fragmentation has occurred in the last 30 years, making the direct estimation of traffic difficult. The work described here can help to solve the problem of estimating traffic flows and in particular the congestion phenomenon through a very cheap approach by using remote sensing and geographical information system technology. This method is based on the identification of attractor points that draw traffic flows such as malls, schools, offices, shops, etc. that is to say, points in a territory that attract a certain number of people with vehicles (estimated with a scale) in specific periods of the day. The identification of those points and the calculation of the urban density through the satellite image processing have allowed the creation of a congestion map for the study area. Then the road network and the buildings have been classified according to the congestion values. The results highlight the most critical and congested areas that affect the traffic flows and impact the quality of life.
\end{abstract}

\section{Keywords}

GIS, Sentinel 2A, Attractors, Kernel Density, IDW, Traffic Flow, Traffic Congestion 


\section{Introduction}

Few research studies have focused on urban traffic, which is characterized by fragmented traffic flow and short sections of roads and which differs significantly from continuous highway traffic [1]. The dynamics of traffic flows in urban road networks are now being studied on computer simulations. Recently, different ways of classifying vehicular traffic movements in big cities have been proposed. They consider the phenomenon as a dynamic flow of particles starting from different "Origin" points and arriving at other points of "Destination". Urban traffic arises from the overlapping of Origin-Destination (OD) flows [2]. Unfortunately, the calculation of these OD matrices of the volume of traffic along these links, both in static and dynamic form, requires a very high cost in data collection and above all for the simulation of large-scale networks. Therefore, different authors propose a traffic model: for example a new approach of an alternative departure time model using a combination of static OD matrices and multiple time series on each origin for modelling dynamic traffic flows in a transportation network is proposed [3]. Alternatively, traffic cellular automata (TCA) models based on statistical mechanics are used [4]. However, taking into account that traffic data are highly nonlinear and complex, often varying also with the hours of the day, other authors use chaos theory that would allow to distinguish between random, probabilistic and deterministic systems [5]. In terms of chaotic traffic, Disbro and Frame [6] also demonstrate how the theoretically derived traffic model, where a vehicle accelerates in response to the speed and distance of the vehicle preceding (Gazis-Herman-Rothery Car-Following Model), is highly chaotic even when applied to small systems (only eight cars) [7].

Furthermore for Richards, the traffic flow theory is developed by replacing individual vehicles with a continuous "fluid" density and applying an empirical relationship between speed and density [8]. In another case, Bicakci et al. in a study in Istanbul, Turkey, try to integrate dynamic speed data from the urban navigation road network taken in real time in a static transport scenario test model or TRANSTOOLS ("INSTRUMENTS for transport forecasts and scenario test"). To associate and integrate the velocity data, they designed a framework with the spatial interpolation methods comprising the fixed-width buffer method and Inverse Distance Weighting (IDW) [9].

To avoid expensive field measurements in a large street complex such as that of the entire municipality of Rome $\left(1283.7 \mathrm{Km}^{2}\right)$, we designed a Geographic Information System (GIS) based on an indirect methodology focused on traffic "attractors" through measurements of urban density and indicators of traffic congestion that impact the residents' quality of life.

An "attractor" intends to be any point in a complex network that attracts traffic flows: shopping malls, schools, offices, shops and so on; that is, points in a territory that attract a certain number of people with vehicles (estimated with a scale [weight] from 1 to 10 ) in specific periods of the day, calculated in total hours [10]. This work offers an application to simulate destination flows without 
the need to assign individual routes and to help avoid the complexity of a big city like Rome. In this paper, we address the problem by using a very simple model in which both structure and dynamics are controlled by the traffic attractors location in the urban space.

\section{Study Area}

In Italy the administrative boundaries are characterized by three levels: Region (20), Province (88)-Metropolitan Area (14) and Municipality (7914). This research study focuses on the entire municipality of Rome which covers a large territory of around $1290 \mathrm{~km}^{2}$ located in Lazio Region within the Metropolitan Area (Province) of Rome (Figure 1). The Lazio Region has a total of about 5.6 million inhabitants divided into 5 Provinces. The Province of Rome, now called Metropolitan Area, includes 120 municipalities without Rome 1.4 million inhabitants. Only the municipality of Rome has 2.86 million inhabitants which reside not only within the ring road called GRA, but also in the whole municipal territory, dispersed in numerous suburbs. The acronym GRA stands for Grande Raccordo Anulare (literally "large ring road"). It is an orbital highway in the shape of a toll-free ring, $68.2 \mathrm{~km}$ in circumference, that surrounds Rome. The city of Rome is one of the urban agglomerations that have experienced one of the fastest rates of growth in recent years in Italy [10].

The GRA is an essential artery for the mobility of the capital, in fact, it acts as an external ring road for the connection of the peripheral areas of Rome, allowing motorists to reach the different areas of the city by traveling externally, thus avoiding passing through the city center. Furthermore, it is a highway connection to the main national roads. The importance of the GRA is also evident in the following numbers: 150 thousand to 180 thousand vehicles travel the GRA every day. It is also necessary to highlight the establishment of the new large shopping centers in the GRA area, which, especially during the weekends, are the main attractions for the movement within the city with the consequent increase in the radial traffic. A recent survey carried out by the Mobility Agency on

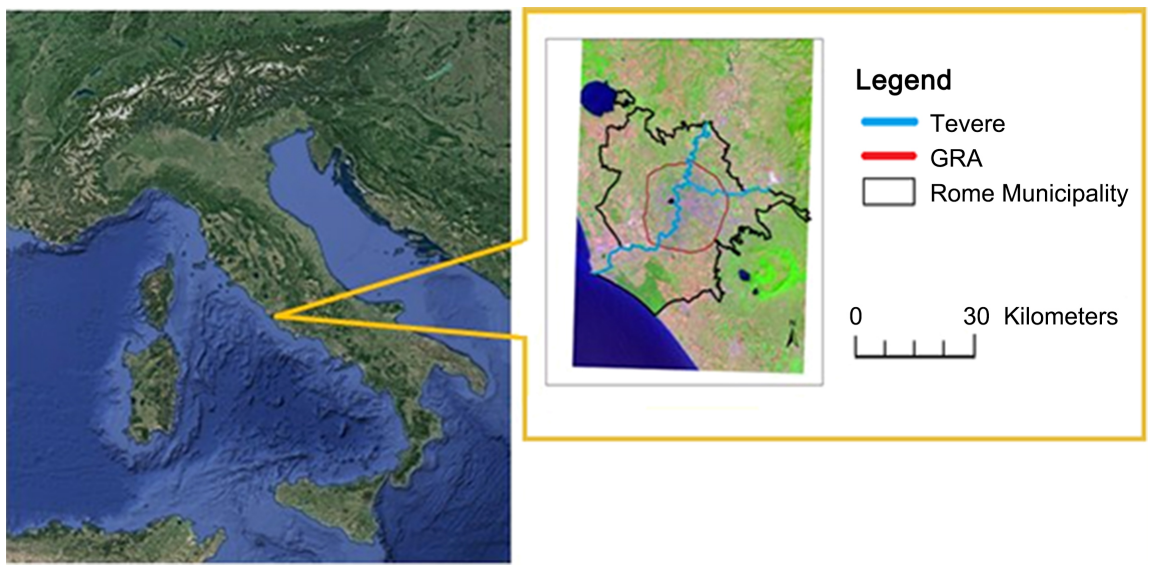

Figure 1. Study area. On the left: Italy (Google Earth image); on the right: the Rome municipality boundaries. 
the 5 biggest shopping centers in Rome involved over 170,000 visitors on Saturday. The survey found that $88 \%$ of the visitors used cars, while only $5.9 \%$ of the visitors used public transport [11].

These new malls are not adequately supported by the public and private infrastructure system and have had great impacts on traffic flows. The GRA suffers from the progressive increase in residential settlements in the suburbs of the municipality of Rome despite three-lane extension works. The displacements and the relationship between displacements and the number of inhabitants is a critical issue in fact this relationship represents a synthetic indicator of the reduced efficiency of the city in terms of accessibility and habitability, with repercussions on social inclusion and competitiveness. All these origin-destination displacements are due to points of attraction or more simply attractors.

Those points such as offices, schools, shops, shopping centers, banks, religious buildings, local markets, etc. (Figure 2) attract traffic of people and vehicles at certain times for variable durations.

An increase in these attractors in certain areas causes traffic congestion, which impact the whole urban system. Starting from our past studies conducted at the European Space Agency since the early 1980s [10] [12] this analysis examines the current effects of the urbanization process on vehicular traffic in the vast Roman urban area. Our recent works have highlighted these phenomena for the area of the Castelli Romani using 259 attractors and for the border area between Rome and some municipalities of the Castelli Romani such as Frascati, Grottaferrata and Marino taking into consideration 530 attractors [13] [14]. In the case that we are now going to discuss, we have taken into consideration the whole area of the municipality of Rome $\left(1287 \mathrm{Km}^{2}\right)$ and we have identified 1347 points of attraction for which a weight and a timetable have been calculated (Table 1). From the analysis of these attractors, we have detected the congestion values that impact the residents' quality of life.

Table 1. Taken from the GIS table of the attractors.

\begin{tabular}{cccccccc}
\hline ID & P (weight) & T (hour) & Val1 & class & Val2 & Gridcode & Area \\
\hline 20 & 10 & 12 & 10.95 & hospital & 7.40 & 5 & 10,000 \\
21 & 10 & 12 & 10.95 & station & 7.40 & 5 & 10,000 \\
23 & 10 & 10 & 10 & station & 7.40 & 5 & 4058.17 \\
28 & 8 & 8 & 8 & $\begin{array}{c}\text { shopping } \\
\text { center }\end{array}$ & 6.32 & 5 & 10,000 \\
29 & 8 & 8 & 8 & $\begin{array}{c}\text { shopping } \\
\text { center }\end{array}$ & 6.32 & 5 & 10,000 \\
30 & 8 & 8 & 8 & $\begin{array}{c}\text { shopping } \\
\text { center }\end{array}$ & 6.32 & 5 & 10,000 \\
25 & 10 & 3 & 5.48 & school & 4.05 & 3 & 10,000 \\
\hline
\end{tabular}




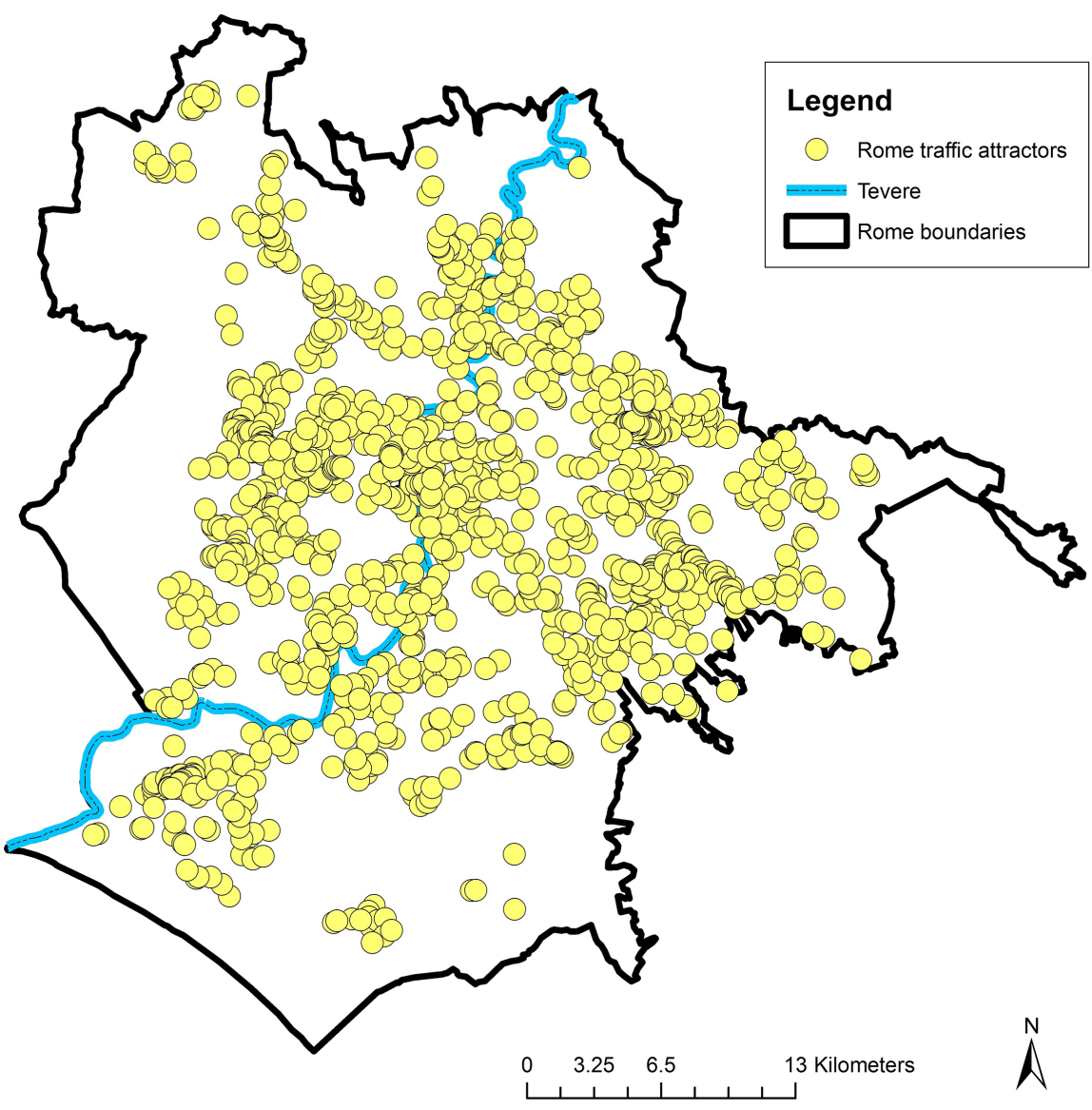

Figure 2. The 1347 points of attraction distributed throughout the municipality of Rome.

\section{The Problem of Traffic in Rome}

The city of Rome boasts 2700 years of history and some of the most important works dating back to antiquity are the streets. Citing V. W. von Hagen “... Roman roads are an incalculable factor of importance in the very history of humanity, Rome became a mobile source of civilization and the mistress of the world precisely because through its streets it had managed to systematically control most of the earth's surface" [15].

Even today, modern Rome uses the routes of the "consular" roads (Figure 3), so called because they were built by the consuls of the time. Certainly, the traffic load of ancient Rome was very different from that of today.

Recently the data of the "Traffic Index", Tom Tom's annual research on the level of traffic, carried out by examining 403 cities in 56 countries around the world, show that Rome is the first on the list in Italy (Table 2), the city where people spend on average 39\% more time in traffic [16]. Compared to other European cities, Rome is ranked 31 in global traffic level, while London is ranked 40, Paris 41 and Madrid 228.

In developing countries, the urban traffic is increasing rapidly with growing concern [17] [18]. The mitigation of traffic congestion is one of the primary goals of transportation authorities and researchers [1]. Certainly, Rome is not 


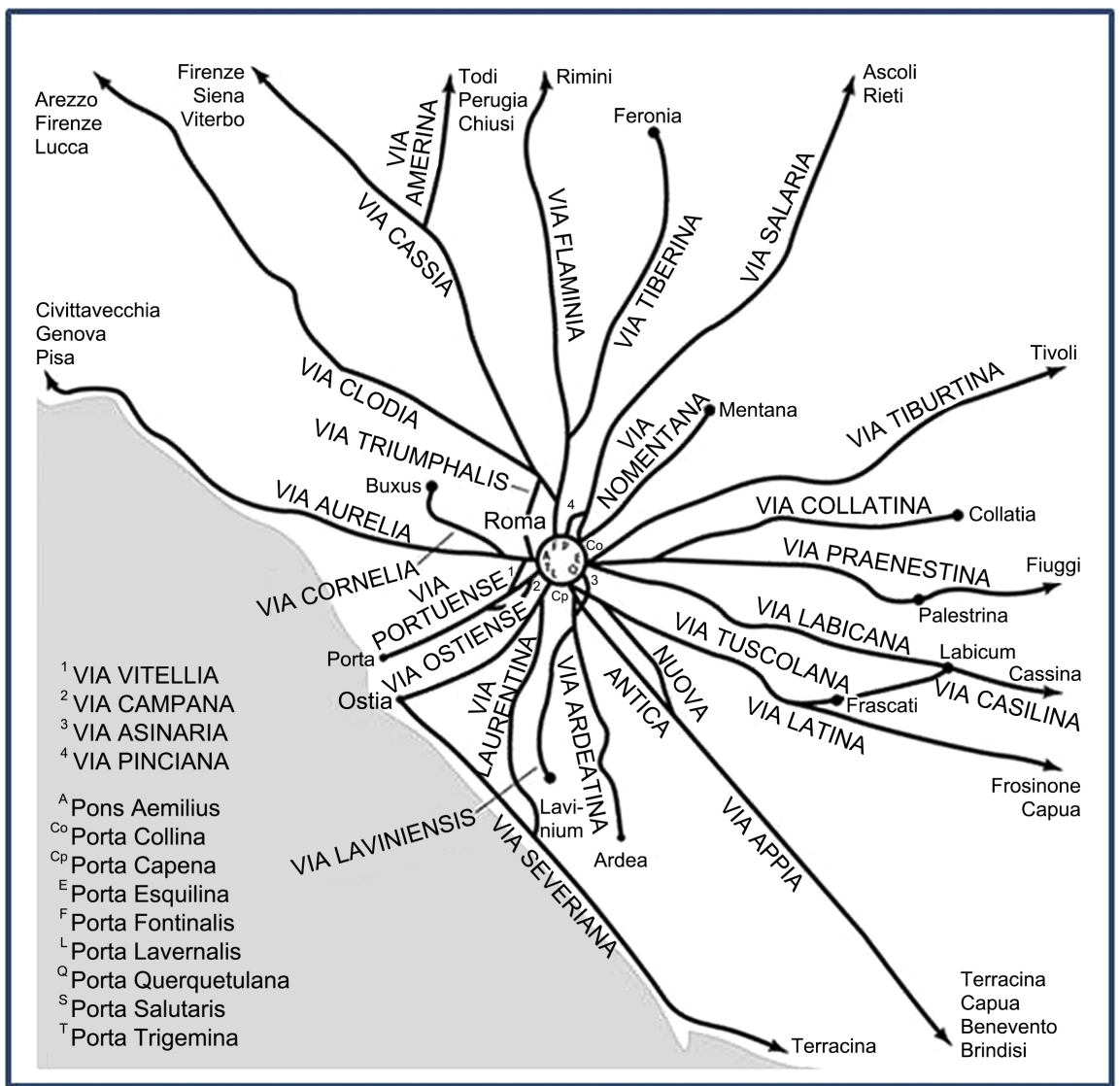

Main Roman consular roads:

- Via Aurelia: from Roma to Luni.

- Via Cassia: from Roma to Massa.

- Via Flaminia: from Roma to Rimini.

- Via Salaria: from Roma to San Benedetto del Tronto.

- Via Tiburtina: from Roma to Pescara.

- Via Casilina: from Roma to Santa Maria Capua Vetere.

Figure 3. The roads of Rome in ancient times (Credit: Maximilian Dörrbecker) [15].

Table 2. Taken from the GIS table of the attractors.

\begin{tabular}{cccccc}
\hline Ranking & City & $\%$ & Ranking & City & $\%$ \\
\hline 1 & Roma & 39 & 6 & Milano & 30 \\
2 & Palermo & 35 & 7 & Catania & 28 \\
3 & Messina & 32 & 8 & Bari & 27 \\
4 & Genova & 31 & 9 & Reggio Calabria & 27 \\
5 & Napoli & 30 & 10 & Bologna & 25 \\
\hline
\end{tabular}

yet at the level of Mumbai (first in the world with 65\% of travel time spent in a car), but the situation is critical and is due to a series of choices on urbanization policy without effective control.

In the morning rush hour, the population present in the metropolitan area 
(municipality of Rome plus its province) generates a total of 715 thousand displacements of which more than 50\%, 393 thousand people, are born and die within the GRA [11].

All the PRG (Piano Regolatore Generale, i.e. the urban planning) of both Rome and neighboring municipalities have been designed for maximum urban growth. Private houses and buildings for schools, offices, shops and shopping centers have been distributed without a clear idea of the effects on mobility, even considering that in Italy priority was given to cars and not to public transport. So on a daily basis the streets of Rome receive such a quantity of private and commercial traffic that a minimum slowing down or an accident can block circulation for a considerable amount of time.

Over the last twenty years the city of Rome has experienced the now worldwide phenomenon of urban sprawl [11] [19] occupying almost the entire municipal territory, expanding in particular in the east and south-west areas and also pouring into the municipalities neighbors. The latter have absorbed ever greater shares of new inhabitants, increasing enormously their resident population, so that the system of exchanges between Rome and the rest of the region is now conditioned by this new structure and has undergone profound changes over the last two decades. In fact, the phenomenon of commuting is suffering an increase in the average distances of systematic home-work displacements with the consequent amplification of congestion problems on the road network.

\section{Materials and Methods}

This work has been carried out at ESRIN, the establishment of the European Space Agency (ESA) in Italy, located in Frascati, near Rome, by using ERDAS/IMAGINE 2015 and GIS ArcInfo 10.7.1 data processing software in order to perform analyses of satellite images, orthophotos and cartographic maps. Both images and maps are projected in the UTM geographic system, 1924 international ellipsoid, 1950 European Datum (Table 3).

Table 3. Satellite images, maps and aerial photos used in this research study.

\begin{tabular}{ccccc}
\hline \multicolumn{1}{c}{ Mission } & Sensor & Product type & Resolution & Year \\
\hline CTR MAP & & Map & $1: 10,000$ & 1990 \\
Aerial imagery & Volo Italia & Ortophoto & PAN $50 \mathrm{~cm}$ & 2000 \\
Aerial imagery & Volo Italia & Ortophoto & Color $50 \mathrm{~cm}$ & 2005 \\
ALOS & AVNIR2 & MS & $10 \mathrm{~m}$ & 2010 \\
SENTINEL-2A & MSI & MS & $10 \mathrm{~m}$ & 2018 \\
SENTINEL-2A & MSI & MS & $10 \mathrm{~m}$ & 2020 \\
PLEIADES 1A & OLI & PAN + MS & $\begin{array}{c}50 \text {-cm color } \\
\text { (pansharpened })\end{array}$ & $2015-2016$
\end{tabular}




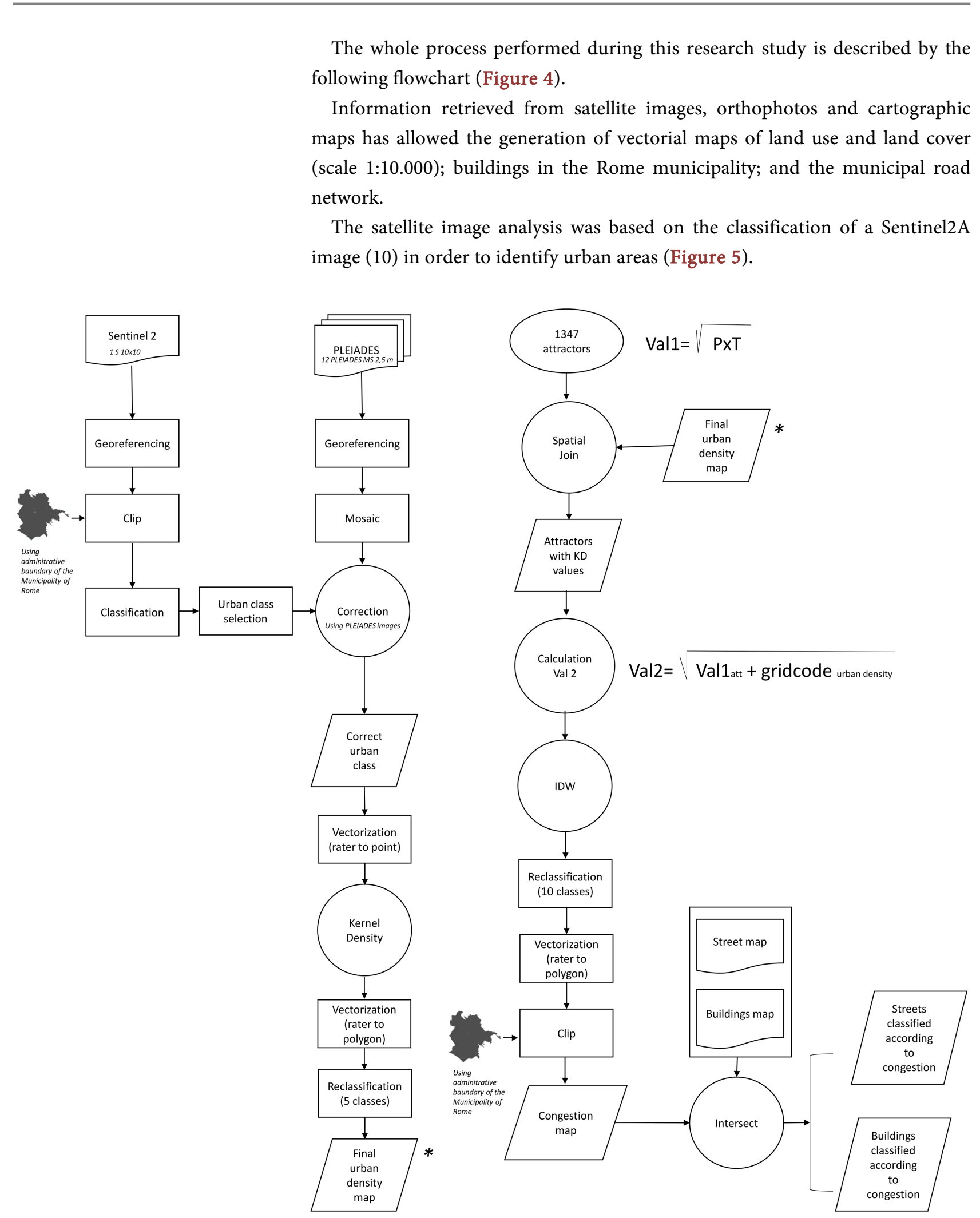

Figure 4. Flowchart that describes the whole process performed during the research study. On the left: the satellite image processing to select the urban class and to calculate the urban density (marked with ${ }^{\star}$ ). On the right: the congestion map as the result of the combination of 1347 attractor points and the above mentioned urban density map. The road network and the buildings have been classified according to the congestion values. 


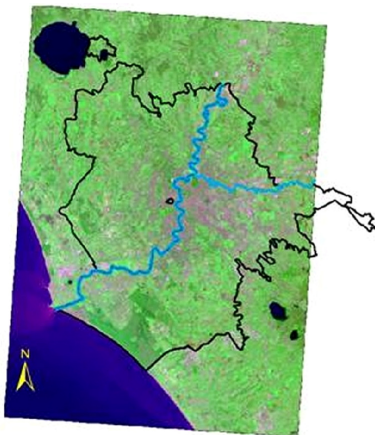

(a)

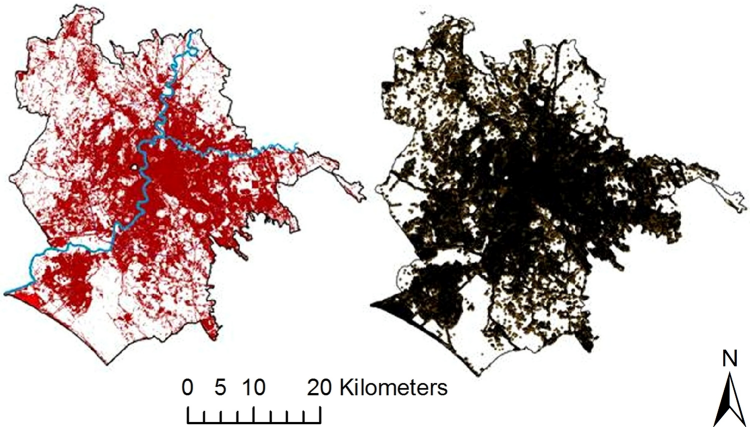

(b) (c)

Figure 5. Rome municipality - (a) Sentinel2A 2018 image bands 3, 4, 1 RGB; (b) Rome urban class (polygons); (c) Polygons of the urban class transformed into a set of points according to the size of the building.

The Gaussian Maximum Likelihood Classifier (MLC) with 17 categories of land use from vegetation and urban areas to agricultural lands was used to identify and to separate different components of the landscape. For this research we considered and extracted only the class that referred to the built area. As described in the flowchart, this selected class was corrected using a mosaic of 12 images of Pleiades (2.5 m multispectral).

The urban class was vectorized and transformed by polygons into a set of points related to the size of the building. The Kernel Density Estimation (KDE) was then applied by calculating the urban density in 5 density classes. The KDE function, which provides the estimate of a punctual phenomenon by generating a surface from a set of points distributed in a region of space. This function weights the values selected within a sphere of influence as a function of their distance from the point where the intensity is estimated. The density or intensity of the attractors' distribution in the point $\mathrm{s}$ can be defined with the following equation:

$$
\lambda_{(s)}=\sum_{i=1}^{n} \frac{1}{\tau^{2}} K\left(\frac{s-s_{i}}{\tau}\right)
$$

where $\lambda(s)$ represents the estimate of the distribution of points measured in the point $s, s_{i}$ is the i-th event (value), $K$ the Kernel function and $\tau$ the threshold that permits obtaining more or less rounded surfaces [10]. The resulting grid file has been vectorized, considering its 5 density classes (Figure 6).

In the study area 1347 attractor points have been identified using ISTAT (Italian National Institute of Statistics) publications, Google maps and, more generally, with the help of commercial internet databases, and the authors' personal knowledge of the study area. Therefore, the value Val of an attractor has been calculated considering the product of its weight (heavy or congested traffic) multiplied by the total of associated hours of these specific traffic conditions, as follows:

$$
\text { Val1 }=\sqrt{P \times T}
$$




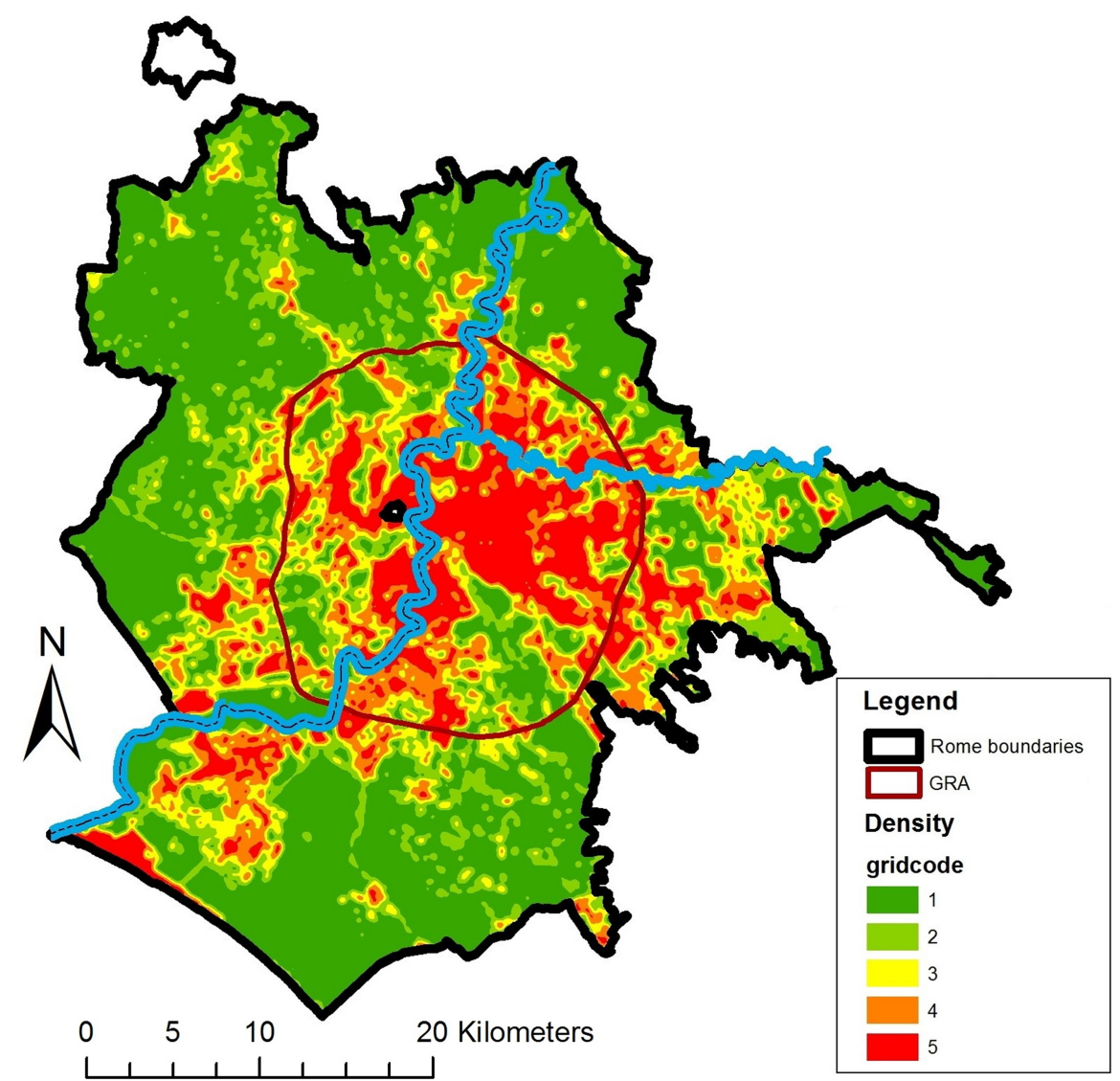

Figure 6. The five density classes.

where $P$ is the weight related to the traffic conditions, hence to the number of people involved, and $T$ the associated total traffic period in hours [10].

It must also be kept in mind that urban traffic increases or decreases according to different periods of the year and according to society habits, so that in Italy and especially in winter, the start of school, the opening of public or private offices and businesses are scheduled around 8.00 a.m. with consequent morning congestion occurring from 7.00 to 9.00 a.m. Congestion also occurs during the closing of schools from 12.30 to 14.30 p.m.; offices and factories from 16.00 to 18.00 p.m. and finally businesses from 19.00 to 20.00 p.m. Where the total flow for these hours is nothing but a sum of the relative flows over time. Calculations have been made over 24 hours, but with an analysis over a total or a sum of hourly fluxes on the basis of the observation of the attractor type. For example, in Italy a high school with 1000 students causes a nontrivial traffic problem, with repercussions in a big area. These schools can "attract" teachers, parents and students, but only at certain hours: the first part of the morning and at the end of lessons, with repercussions on the traffic during a total period of up to 3 hours; hence, these " 3 hours" have been assigned the maximum weight of 10 (traffic congestion). In the case of the school mentioned above, the value of this attractor is 5.4, that is to say the square root of the product of 3 hours for the maximum value of 10 . The 1347 attractors have been joined (spatial join) with the 
urban density map in order to have an urban density value for each attractor point. Then the following formula has been applied:

$$
\text { Val2 }=\sqrt{\text { Val1+ Gridcode }}
$$

where Val1 is the attractors value and Gridcode is the urban density value [10].

Values of these points have been interpolated by applying the IDW geostatistical function and creating another grid surface. IDW is a technique of interpolating a surface using an inverse weighted distance. The inverse weighted distance method is based on the weighted average of the scatter points with the weight assigned to each scatter point that diminishes as the distance from the interpolation point increases. The result is a raster file that has been reclassified into 10 classes to get the best detection (Figure 7). The raster has then been vectorized and clipped using the administrative boundary of the Rome municipality. This final map is called "congestion map".

Finally, we have classified the road network and the buildings map according to the congestion map. These outputs highlight the impact of the traffic congestion on the quality of life (Figure 8).

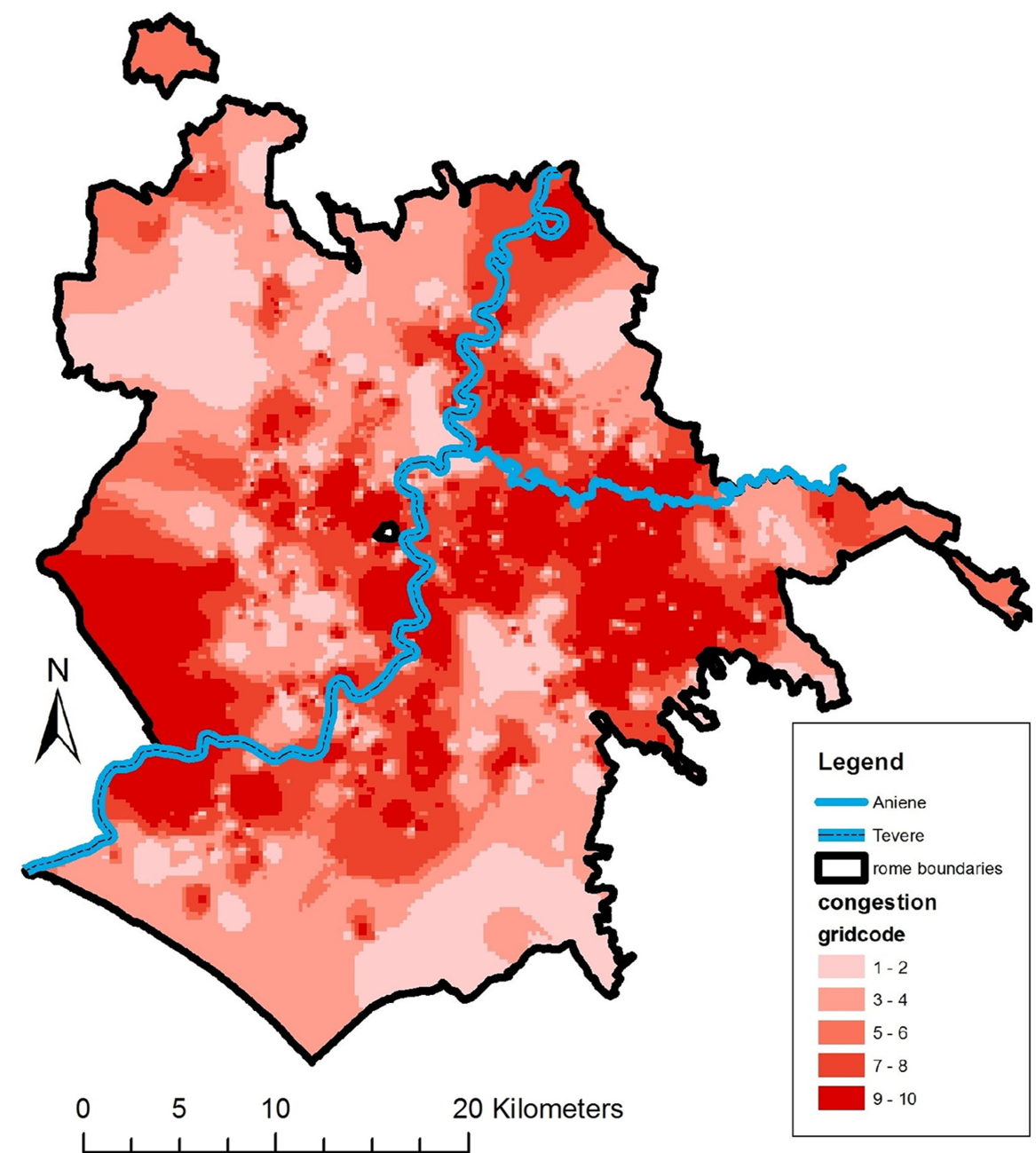

Figure 7. The map of the 10 classes of congestion. 


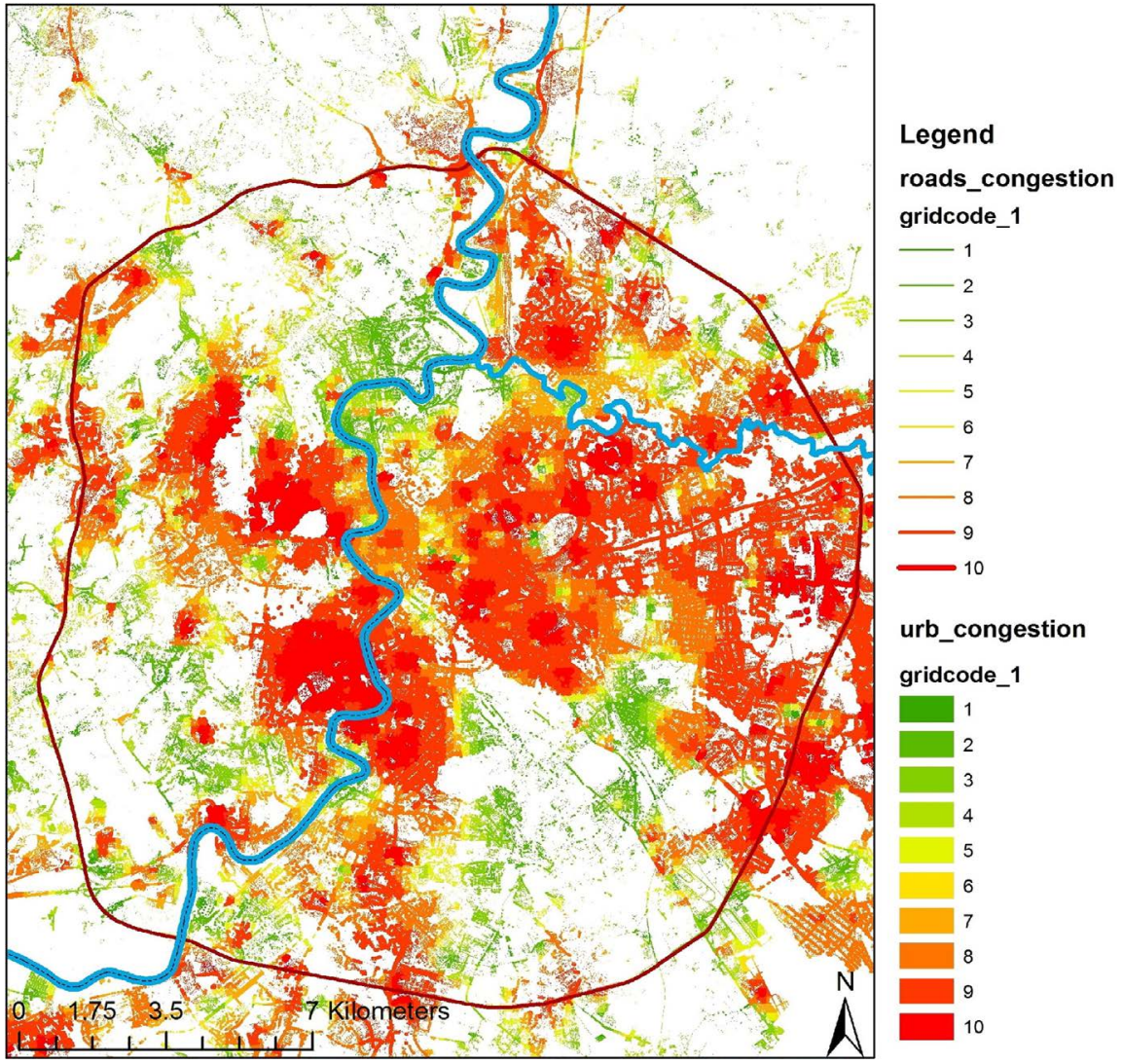

Figure 8. From green (low) to red (high) the congestion map of buildings and roads.

Our work, which starts with the survey of land use with analysis of satellite images and continues with GIS methods to identify traffic congestion in the municipality of Rome with the attractors' method, has highlighted the most critical and congested areas.

By dividing the entire municipal territory into quadrants (Figure 9), we can easily notice that the NE quadrant is the most congested. This quadrant is characterized by via Tiburtina and the Rome-Teramo motorway where the traffic is significantly reduced in speed, especially during working hours. The SE quadrant also receives important traffic flows and shows numerous moments of congestion along the consular roads Prenestina, Casilina, Tuscolana and Appia. The traffic of the NW quadrant includes the streets Cassia, Flaminia and Salaria. Finally, the SW quadrant shows congestion on the via Aurelia and via Ostiense. It is hypothesized that much of the traffic involves the GRA that we observe congested for most of the day.

Recent studies of the University of Rome "La Sapienza" [19] have been carried out to identify an alternative to the GRA where the traffic could flow out. Actually, the project has identified 9 alternatives and one of those would flank the GRA in the SE area.

Many critics have defined it only as a palliative. Taking into account the time needed to build it, the traffic situation in Rome may approach paralysis in the meantime. 


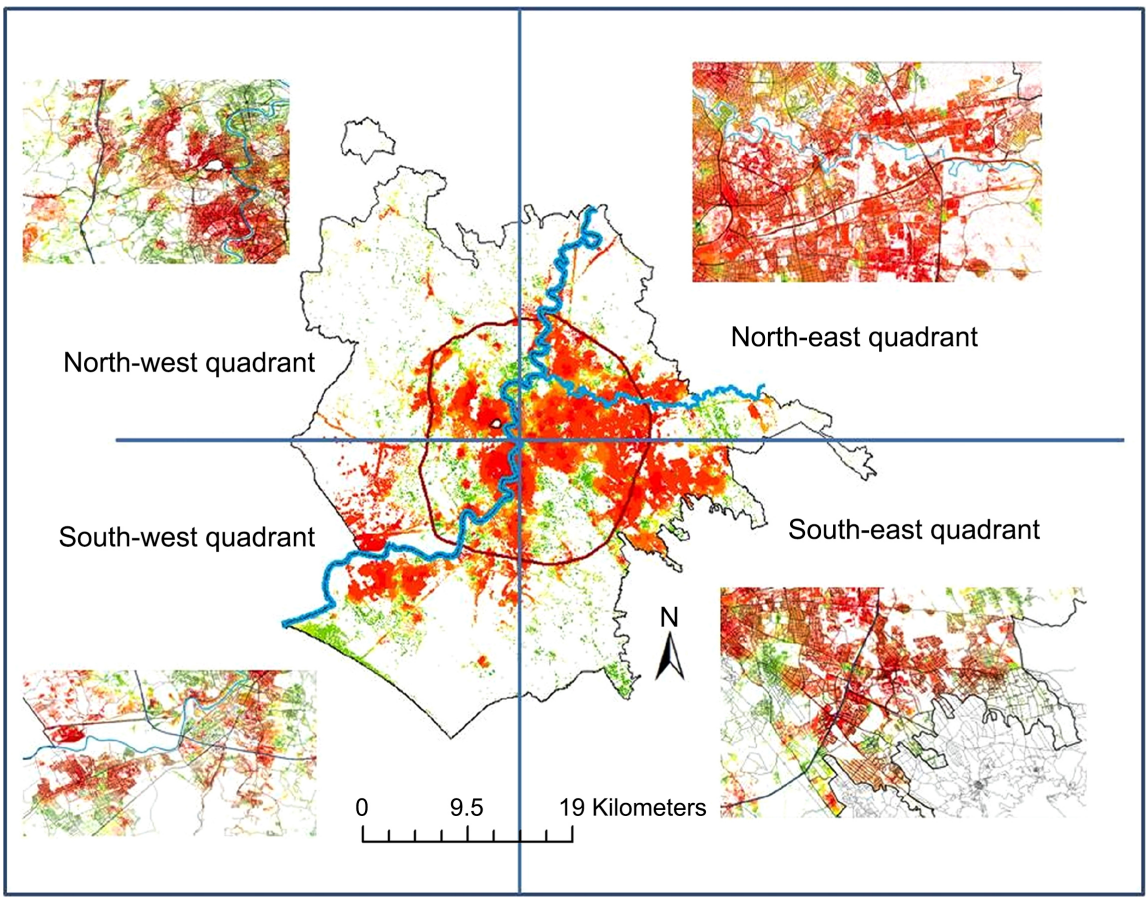

Figure 9. The five density classes. Zoom scale 1:300.000.

The lack of serious planning and the "laissez faire" policy have caused the current urban chaos. Certainly, a better organization of public transport systems and above all a different distribution of urban functions could make the city of Rome more habitable.

\section{Conclusions}

The results of this study strongly suggest a situation of a municipality that has undergone an important building expansion in the last twenty years without adequate land planning [20].

Obviously, the indirect method used in this study does not provide accurate data such as those obtained with the classic direct measurements of traffic congestion and does not intend to replace them. On the contrary, it should be useful to get a general idea of traffic congestion in a given area by identifying critical problems at low cost. However, our proposed method is sufficient to allow local administrators to plan interventions and allocate resources while minimizing the risk of wasting them on unnecessary or low priority actions. The identification of critical points in traffic flows is the first step for selecting appropriate mitigation measures [21]. Microscopic policies are more effective, because they address the problem at the scale at which actual policy decisions are taken [17]. Finally, studies like this can be used in order to optimize a possible direct measurement campaign. The results obtained are very important, not only in terms of knowledge of congestion models, but also in terms of urban regeneration and, therefore, planning for a better quality of life for citizens. An operational GIS of this type should be a key tool for the local governance of any administration. 


\section{Acknowledgements}

This paper and the research behind it would not have been possible without the support of the European Space Agency ESA/Esrin.

\section{Conflicts of Interest}

The authors declare no conflicts of interest regarding the publication of this paper.

\section{References}

[1] Sun, D.J., Liu, X., Ni, A. and Peng, C. (2014) Traffic Congestion Evaluation Method for Urban Arterials: Case Study of Changzhou, China. Transportation Research Record, 2461, 9-15. https://doi.org/10.3141/2461-02

[2] Lakhina, A., Papagiannaki, K., Crovella, M., Diot, C., Kolaczyk, E.D. and Taft, N. (2004) Structural Analysis of Network Traffic Flows. Performance Evaluation Review, 32, 61-72. https://doi.org/10.1145/1012888.1005697

[3] Kemper, C. (2005) Dynamic Traffic Flow Model-A New Approach with Static Data.

[4] Maerivoet, S. and De Moor, B. (2005) Cellular Automata Models of Road Traffic. Physics Reports, 419, 1-64. https://doi.org/10.1016/j.physrep.2005.08.005

[5] Shang, P., Li, X. and Kamae, S. (2005) Chaotic Analysis of Traffic Time Series. Chaos, Solitons and Fractals, 25, 121-128.

https://doi.org/10.1016/j.chaos.2004.09.104

[6] Disbro, J.E. and Frame, M. (1989) Traffic Flow Theory and Chaotic Behavior.

[7] Gruesbeck, C. (2012) Gazis-Herman-Rothery (GHR) Car-Following Model.

[8] Richards, P.I. (1956) Shock Waves on the Highway. Operations Research, 4, 42-51. https://doi.org/10.1287/opre.4.1.42

[9] Bicakci, Y.S., Sarica, B., Pakdil, M.E., Yazirli, B. and Demirel, H. (2017) Spatio-Temporal Analyses to Estimate Speed Information for Transport Forecasting and Scenario Testing. Fresenius Environmental Bulletin, 26, 100-106.

[10] Loret, E., Gullotta, G., Fea, M. and Sarti, F. (2012) Traffic Fluxes and Urban Congestion: A Simple Approach with the Attractors' Method. Journal of Geographic Information System, 4, 494-502. https://doi.org/10.4236/jgis.2012.46054

[11] Assessorato Trasporti e Mobilità (2014) Piano Generale del Traffico Urbano di Roma Capitale-dalle Regole ai Sistemi.

[12] Loret, E., Martino, L., Fea, M. and Sarti, F. (2015) Integration of Historical Maps and Multi-Temporal Optical Remote Sensing Data into a GIS System for Studying of the Large Roman Urban System Expansion since the Early Twentieth Century. Mapping Urban Areas from Space Conference ESA-ESRIN.

[13] Loret, E., Martino, L., Fea, M. and Sarti, F. (2015) Combined Remote Sensing and GIS Techniques for Studying the Large Roman Urban System Expansion during the Last Twenty Years. Advanced Remote Sensing, 4, 48-62. https://doi.org/10.4236/ars.2015.41005

[14] Loret, E., Gullotta, G. and Sarti, F. (2019) Traffic Analysis of the Roman Urban Context Simple Approach with the Attractors' Method. Infrastructures Planning and Monitoring Conference ESA/ ESRIN, December 2012, 494-502.

[15] von Hagen, V. (1989) Le grandi strade di Roma nel mondo. 
[16] The TomTomTraffic Index. https://www.tomtom.com/blog/road-traffic/urban-traffic-congestion

[17] Arnott, R., Rave, T. and Schöb, R. (2005) Alleviating Urban Traffic Congestion. MIT Press, Cambridge, Massachusetts, 240. https://doi.org/10.5860/CHOICE.43-5377

[18] Jain, V., Sharma, A. and Subramanian, L. (2012) Road Traffic Congestion in the Developing World. Proceedings of the 2nd ACM Symposium on Computing for Development, DEV 2012, March 2012, 1-10. https://doi.org/10.1145/2160601.2160616

[19] Secchi, R. (2010) Future GRA-Il futuro del Grande Raccordo Anulare nella prospettiva della città metropolitana, Prospettiv.

[20] Borgomeo, V. (2019) Traffico, Roma peggio di New York, La Repubblica.

[21] Mohan Rao, A. and Ramachandra Rao, K. (2012) Measuring Urban Traffic Congestion-A Review. International Journal of Traffic and Transportation Engineering, 2, 286-305. https://doi.org/10.7708/ijtte.2012.2(4).01 